\title{
Assessment of the Prevalence of Extended-Spectrum Beta Lactamase Producing Gram-Negative Bacilli at the Cdg- Chup, Ouagadougou
}

\author{
Sanou $\mathrm{M}^{1,2,5 *}$, Ky/Ba $\mathrm{A}^{1}$, Coulibali $\mathrm{P}^{1}$, Nagalo $\mathrm{M}^{4}$, Ouedraogo $\mathrm{S}^{3}$, Tamboura $\mathrm{M}^{2}$, Kambire $\mathrm{D}^{2}$, Bisseye $\mathrm{C}^{4}$, Bakiono $\mathrm{F}^{3}$, Simpore $\mathrm{J}^{4}$ and \\ Ouedraogo $\mathbf{R}^{1,2}$ \\ ${ }^{1}$ Training and Research Unit in Health Sciences, (UFR-SDS), University of Ouagadougou, Burkina Faso \\ ${ }^{2}$ Charles-de-Gaulle paediatric University Hospital (CHUP-CDG), Burkina Faso \\ ${ }^{3}$ Souro Sanou University Hospital (CHU-SS), Bobo Dioulasso, Burkina Faso \\ ${ }^{4}$ Pietro Annigoni biomolecular Research Centre (CERBA)/LABIOGENE, University of Ouagadougou, Burkina Faso \\ ${ }^{5}$ General Lamizana Camp Medical Centre, Burkina Faso
}

\begin{abstract}
Introduction: The bacterial resistance to antibiotics is becoming a serious concern in developing countries due to precarious hygiene conditions, inappropriate prescription as well as self-medication and free sale of antibiotics.

The general objective of this study is to assess the prevalence of strains producing ESBL in the BGN isolated in the CHUP-CDG laboratory.

Methods: It is a prospective cross-sectional descriptive study conducted from 1 May to 12 August 2014.

The study was conducted in the Charles De Gaulle paediatric University Hospital (Ouagadougou) and the Arnaud de Villeneuve CHRU (Montpellier).

Results: Out of the 889 pathological substances analysed, 175 germs have been isolated among which 110 BGN which equal 62.8\%. 48.2\% of our BGN are ESBL +.

Among the 110 BGN we isolated $101 \mathrm{~EB}$ and 9 other BGN. No ESBL was found in the other BGN and 52.5\% of EB were ESBL +. As for the ESBL Phenotype, according to the species/gender $60.4 \%$ of ESBL were $E$ coli and $32 \%$ were $K$ pneumoniae.

$50.9 \%$ of ESBL came from Pus against $41.5 \%$ from Urine.

In addition, $64.6 \%$ of hospitalised patients had an ESBL+ phenotype against $24.5 \%$ for out-patients.

Conclusion: The results show the importance of the phenomenon and should help to better care this scourge because antibiotics despite everything, always save millions of lives.
\end{abstract}

\section{Introduction}

As a global concern, bacterial resistance to anbiotics is becoming a serious worry in the developing countries due to precarious hygiene conditions, inappropriate prescription as well as self-medication and free sale of antibiotics. The secretion of ESBL, a common mechanism of bacterial resistance to ATBs, is becoming a threat to public health. Indeed, the ESBL+ germs are more and more resistant to all betalactams (except cephamycins and Carbapenems). In addition, the plasmids supports have bigger size and have genes resistant to other antibiotics causing BMR emergence [1].

If in the developed countries the extended surveillance and the particular care provided to ESBL carriers have reduced the antimicrobial resistance, on the other hand, in the under-developed countries, the important accessibility to beta-lactams and the abusive use of those molecules contribute to expand the phenomenon [2-4].

In Burkina Faso, in 2007, Ouédraogo et al. [5] reported 15\% of ESBL strains and 33\% in 2013, in a second study, This study aims at contributing to assess the scope of the phenomenon in order to draw the attention on the necessity for emergency measures to fight it.

\section{Methods}

The study was conducted at the Charles De Gaulle Paediatric University Hospital (Ouagadougou) and the Arnaud de Villeneuve CHRU (Montpellier). It is a prospective cross-sectional descriptive study covering 1 May to 12 August 2014. The patients whose sample bacteriological analysis allowed isolating and identifying a BGN were those involved in our study. Patients' or accompanying relatives' consent was received before the beginning of our research.

Correspondence to: Sanou M, Training and Research Unit in Health Sciences, (UFR-SDS), University of Ouagadougou, Burkina Faso, E-mail: mahamoudsanou@hotmail.com

Key words: ESBL, enterobacteria, gram-negative bacilli, hospitalised, out-patients Received: September 01, 2017; Accepted: September 25, 2017; Published: September 28, 2017 
The isolation procedure was conducted at the CDG CHUP whereas the identification and the sensitivity to antimicrobial agents were done at the ADV-CHRU. The MALDI-TOF (Matrix-Assisted Laser Desorption/Ionisation-Time-Of-Flight) [automated bacteriology], the principle of which is based on mass spectrometry, has permitted the identification through analysis of bacterial protein. The antibiotic susceptibility testing was carried out through the dissemination technique on MH Agar plate according to CA-SFM and the complete automated interpretation was done with Scir Scan. The Khi- deux $(\chi 2)$ test allowed us to compare the quantities at the significance threshold set at $5 \%$.

\section{Results}

\section{Population socio-demographic characteristics}

106 patients were included in our study. Male patients were the majority (54.7\%), giving a sex ratio of 1.2. The age group (1-30) months were the most important one. Out of the 106 patients, $60.4 \%$ were hospitalised against $39.6 \%$ of out-patients. Most of the hospitalised patients were from the surgical ward and represented $59.4 \%$.

66 patients took antibiotics before the bacteriological test and represented $62.3 \%$ (Table 1).

\section{Bacteriological results}

Out of 889 pathological substances analysed, 175 germs have been isolated among which $110 \mathrm{BGN}$ or $62.8 \%$. These $110 \mathrm{BGN}$ were from 106 samples among which 102 monomicrobials and 4 bimicrobials. It was observed a predominance of E. coli (51.8\%), followed by $K$. pneumoniae with 26 germs representing $23.6 \%$. P. aeruginosa came in third position with 7 germs representing $6.4 \%$. Most of our germs were found in urine and pus with respectively 55 cases (50\%) and 46 cases (41.8\%).

Out of the 110 germs isolated, 53 (48.2\%) produced an extended spectrum of Beta Lactamase. We also noted 101 enterobacteria and 9 other BGN. No production of extended spectrum of bêta-lactamase

Table 1. Socio-demographic characteristics.

\begin{tabular}{|l|l|l|}
\hline Age (months) & Number (n) & Percentage (\%) \\
\hline$<1$ & 9 & $8 \%$ \\
\hline$[1-30]$ & 39 & $37 \%$ \\
\hline$[31-60]$ & 7 & $7 \%$ \\
\hline$[61-120]$ & 24 & $23 \%$ \\
\hline$[121-180]$ & 14 & $13 \%$ \\
\hline$>180$ & 13 & $12 \%$ \\
\hline Total & 106 & $100 \%$ \\
\hline Sex & Number (n) & Percentage (\%) \\
\hline Male & $\mathbf{5 8}$ & $55 \%$ \\
\hline Female & 48 & $45 \%$ \\
\hline Total & 106 & $100 \%$ \\
\hline Status & Number (n) & Percentage (\%) \\
\hline Hospitalised & 64 & $60 \%$ \\
\hline Out-patients & 42 & $40 \%$ \\
\hline Total & 106 & $100 \%$ \\
\hline Services & Number (n) & Percentage (\%) \\
\hline Surgery & $\mathbf{3 8}$ & $\mathbf{5 9}$ \\
\hline Older children & 7 & 11 \\
\hline Infectious diseases & 5 & 8 \\
\hline Neonatology & 5 & 8 \\
\hline Infant & 4 & 6 \\
\hline Others & 5 & 8 \\
\hline Total & 64 & 100 \\
\hline & & \\
\hline
\end{tabular}

was observed in the other BGN; the 53 ESBL producing germs were enterobacteria and represented $52.5 \%$. As for the ESBL Phenotype, according to the species/gender $60.4 \%$ of ESBL were E coli and $32 \%$ were $K$ pneumoniae, $5.7 \%$ were Enterobacter cloacae and $1.9 \%$ were Providencia stuartii (Table 2). Most ESBL were found with Escherichia coli and Klebsiella pneumonia both representing $92.4 \%$ cases respectively equivalent to $60.4 \%$ et $32 \%$ of the cases. In relation to each species, strong prevalence of ESBL has been observed: 65.4\% Klebsiella pneumoniae had the ESBL phenotype; then came Escherichia coli with $56.1 \%$ cases; Enterobacter cloacae and Providencia stuartii were in third position with each $50 \%$ of cases (Table 2).

The ESBL production frequency was $24.5 \%$ in out-patients and $64.6 \%$ in hospitalised ones. The value of $\mathrm{p}<0.05$ implies that there is a significant difference between the ESBL production in hospitalised and out-patients. There are about 6 times (Odds Ratio $=5.64)$ more ESBL production risks in hospitalised patients than in non-resident ones (Table 3). 79.2\% ESBL production germs came from patients who had taken antibiotics in the last 3 months before the bacteriological test (Table 4). 32.1\% ESBL production germs were found in patients aged 1 to 30 months; then came those between 61 and 120 months with 26.4 $\%$ (Table 4). Out of the 110 isolates, 43 (39.1\%) manifested a resistance phenotype to beta-lactams different from the ESBL phenotype. However, no carbapenemase phenotype has been observed (Figure 1).

\section{Resistance phenotypes of our isolates to aminoglycosides}

Out of the 110 isolates, 60 (54.5\%) presented at least one of the resistance phenotypes to aminoglycoside. Klebsiella pneumoniae manifested the highest resistance to aminoglycoside with $69.2 \%$ cases. The GTNt phenotype was mostly represented. No resistance phenotype to aminoglycoside was found in Pseudomonas aeruginosa.

\section{Resistance of our isolates to quinolones}

Out of the 7 Pseudomonas aeruginosa identified, 4 had a reduced sensitivity to quinolones and represented $57.1 \%$. $38.2 \%$ of our isolates had a resistance to all the quinolones. There was more resistance to nalidixic acid with $59.1 \%$ cases. Escherichia coli were the species that showed more resistance to all the quinolones tested and was followed by Klebsiella pneumoniae.

\section{Cross resistance between different antibiotic families}

Among the ESBL phenotype germs, 94.3\% manifested a resistance phenotype to at least one quinolone and one aminoglycosides at the same time. $100 \%$ of ESBL producing germs manifested a resistance phenotype to at least 3 different families of antibiotics.

\section{Discussion}

Males were predominant in our study and represented $54.7 \%$. Ouedraogo et al. [5] made the same observation contrary to Mchich A. in Morocco who noticed a female predominance.

Most enterobacteria (52.5\%) were ESBL producers. This ESBL rate is well above the $9 \%$ observed by Guessennd N. et al. [6] in Abidjan, Côte d'Ivoire in 2006. This confirms the fact that ESBL producing strains are growing over the years. This proportion is close to that of Obeng-Nkrumah et al. [7] in Ghana who found 49.3\% ESBL producing enterobacteria and to those of Dabiré M [8] in Burkina Faso who found respectively $56 \%$ et $63.3 \%$. This high quantity of ESBL producing bacteria in our study can be justified by the very poor health and environmental hygiene conditions, the lack of a rigorous prescription and access to antibiotics in hospitals and drug stores, the 


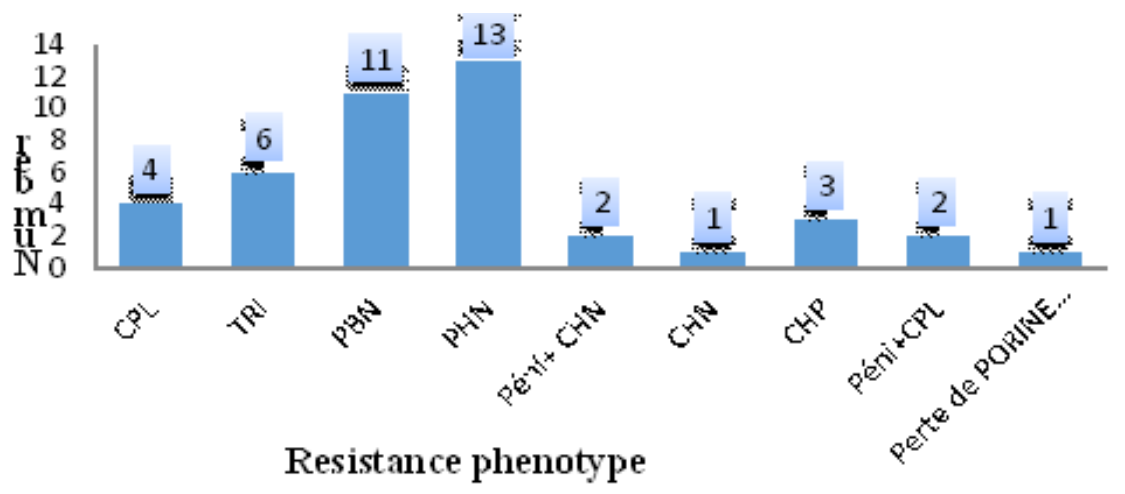

Figure 1. Distribution of the other resistance phenotypes to bêta-lactams.

Table 2. Distribution of ESBL producing germs according to bacterial species identified.

\begin{tabular}{|c|c|c|c|}
\hline \multirow{2}{*}{ Identified species } & Number (n) & $\begin{array}{c}\text { ESBL } \\
\text { Percentage (\%) } \\
\text { (related to ESBL } \\
\text { total : } \mathbf{n = 5 3 )}\end{array}$ & $\begin{array}{c}\text { Percentage (\%) } \\
\text { (related to each } \\
\text { species) }\end{array}$ \\
\hline K. pneumoniae & 17 & 32.0 & $\mathbf{6 5 . 4}$ \\
\hline $\begin{array}{c}\text { E. coli } \\
\text { Enterobacter } \\
\text { cloacae }\end{array}$ & 32 & $\mathbf{6 0 . 4}$ & 56.1 \\
\hline Providencia stuartii & 1 & 5.7 & 50 \\
\hline Total & 53 & 1.9 & 50 \\
\hline
\end{tabular}

Table 3. Distribution of ESBL producing germs according to status at hospital.

\begin{tabular}{|c|c|c|c|c|c|}
\hline \multirow{2}{*}{ STATUS } & \multicolumn{2}{|c|}{ ESBL- } & \multicolumn{2}{c|}{ ESBL+ } & P \\
\cline { 2 - 6 } & $\mathrm{N}$ & $\%$ & $\mathrm{~N}$ & $\%$ & \\
\hline OUT-PATIENTS & 34 & 75.5 & 11 & 24.5 & \\
\hline HOSPITALISED & 23 & 35.4 & 42 & $\mathbf{6 4 . 6}$ & $<0.001$ \\
\hline
\end{tabular}

Yates'Khi square corrected $=15.6 \mathrm{p}=1.710^{-5}$

Odds Ratio $=5.64$

Table 4. ESBL distribution according to socio-demographic characteristics and nature of product.

\begin{tabular}{|l|l|l|}
\hline \multirow{2}{*}{ Age (months) } & ESBL & \\
\hline$[1-30]$ & Number (n) & Percentage (\%) \\
\hline$[61-120]$ & $\mathbf{1 7}$ & $\mathbf{3 2 . 1}$ \\
\hline$[121-180]$ & $\mathbf{1 4}$ & $\mathbf{2 6 . 4}$ \\
\hline$<1$ & 9 & 17.0 \\
\hline$>180$ & 5 & 9.4 \\
\hline$[31-60]$ & 5 & 9.4 \\
\hline Total & 3 & 5.7 \\
\hline Nature of sample & 53 & 100 \\
\hline Pus & & \\
\hline Urine & $\mathbf{2 7}$ & $\mathbf{5 0 . 9}$ \\
\hline Blood & 22 & 41.5 \\
\hline Total & 4 & 7.6 \\
\hline SERVICES & 53 & 100 \\
\hline Surgery & & \\
\hline Infant & $\mathbf{2 4}$ & $\mathbf{5 7 . 1}$ \\
\hline Older children & 4 & 9.5 \\
\hline Infectious diseases & 4 & 9.5 \\
\hline $\begin{array}{l}\text { Neonatology } \\
\text { (Others) }\end{array}$ & 3 & 7.2 \\
\hline Total & 3 & 7.2 \\
\hline Previous antibiotherapy & 4 & 9.5 \\
\hline Yes & 42 & 100 \\
\hline Unknown & $\mathbf{4 2}$ & \\
\hline No & 8 & $\mathbf{7 9 . 2}$ \\
\hline Total & 3 & 15.1 \\
\hline & 53 & 5.7 \\
\hline & & 100.0 \\
\hline
\end{tabular}

street medicines phenomenon, the high cost of life pushing patients to stop treatment well before the deadline. This high ESBL production of our species could also be explained by the fact that many of our germs have been isolated in samples of patients who came back for controls after antibiotic treatment. The isolated germs in these cases confirm the failure of the previous treatment and the germs become more resistant. Guessennd and al. [6] in côte d'ivoire in 2013, suspected the selection constraint used by practitioners and the presence of low concentrations of unmetabolised antibiotics released by the hospital to be a cause of BMR dissemination among which the ESBL producing BGN. A study on the hospitals discharge in Burkina Faso would permit to cast light on this possibility.

\section{The ESBL producing germs according to the bacterial species}

Most ESBL were found in E. coli and K. pneumoniae, both representing $92.4 \%$ cases equalling respectively $60.4 \%$ and $32 \%$ cases followed by Enterobacter $s p$ with $5.7 \%$ cases. Our results are similar to those of Ouedraogo et al. [5] who found in the same order $62.2 \%$, $27.3 \%$ and 4.9 .Indeed, these species are among the commensal enterobacteria of the digestive tract, those that have a great capacity to become pathogenic. E. coli remains influential in the urinary tract infections [9]; urine being the source of most of the samples received, that can explain why E. coli is the most isolated germ and in which more ESBL phenotype was found. Klebsiella is an enterobacteria very disseminated in hospitals and is associated to suppuration and to bacteremia [7]. Pus comes second after urine in the samples and justifies that Klebsiella pneumoniae is the second prevalent germ with the highest ESBL production.

However, considering every bacterial species, we notice there is more ESBL production in Klebsiella pneumoniae (65.4\%), followed by E. coli $(56.1 \%)$. This prevalence is also very important in Enterobacter cloacae and Providencia stuartii with $50 \%$ cases. These figures are as high as those of Obeng-Nkrumah N. et al. [7] in Ghana who found that $75 \%$ Enterobacter cloacae, $61.5 \%$ k.pneumoniae and $43.7 \%$ E.coli showed the ESBL phenotype. Dabiré M [3] found superior figures equalling $69.38 \%$ for Klebsiella sp, $65.88 \%$ for E.coli, 75\% for Enterobacter sp. and $58.33 \%$ for Pseudomonas.

Lonchel and al. [10] in Cameroon in 2012 found 66.7\% isolates of ESBL producing E. coli. This difference of proportions for Pseudomonas and the high proportion for ESBL producing Providencia stuartii might be explained by the low presence of these species in the bacterial population of our study. An important presence of these species would permit to better appreciate the ESBL production. The difference of proportion of ESBL producing Enterobacter sp. compared to the results of Dabiré M [8] and Obeng-Nkrumah [7] can also be justified by the lower quantity of this species in our bacterial population. 
The highest ESBL prevalence in our study has been found with K. pneumoniae. We learn from many studies $[7,11]$ that the ESBL prevalence was higher for K. pneumoniae than for E.coli until the end of the years 1990s but nowadays, they notice an important change of the global epidemiological situation: ESBL producing strains are now mostly E. coli that is responsible for community infections mainly urinary ones. This different result compared to our study could be due to the fact that most of our germs were isolated from hospitalised patients.

\section{According to status at hospital}

The frequency of ESBL production was $24.5 \%$ in out-patients against $64.6 \%$ in hospitalised ones. These figures are similar to those of Dabiré M [8] in Burkina Faso which found 17\% in out-patients against $83 \%$ in hospitalised ones. From these results we can deduce that hospitalisation is a risk factor for ESBL transmission. This observation has been made by Rodriguez-Villalobos and al. [11] in 2006 in Belgium which has mentioned extended hospitalisation as a risk factor for ESBL producing germs dissemination.

\section{According to the sample nature}

One hundred percent (100\%) germs from hemocultures showed the ESBL phenotype followed by pus with $58.7 \%$ cases and urine with 40\%. Ouédraogo [5] in Burkina in 2013 found that $62 \%$ urine and $57 \%$ pus contained ESBL producing germs. Obeng-Nkrumah in Ghana in 2013 [7] observed that $66.7 \%$ urine, $45.6 \%$ hemoculture samples and $0 \%$ pus contained ESBL producing germs. The primacy of hemoculture containing ESBL producing germs in our study might be explained by the low proportion of germs coming from these samples (3/110).

There was an important proportion of ESBL producing germs in pus compared to urine; this result is different from the one of Ouédraogo [5] and Obeng-Nkrumah [7] which found ESBL predominance in urine. Most of the pus in our study has been taken from hospitalized patients and $86.9 \%$ of those patients have taken antibiotics during their hospitalisation just before the sampling for bacteriological test. In addition, the $\mathrm{C} 3 \mathrm{G}$ were the most used with Cefriaxone. Different studies $[9,12]$ show the impact of these antibiotics on the increase of ESBL enterobacteria production. This phenomenon could explain the highest proportion of ESBL producing germs in pus compared to urine.

\section{Other resistance phenotypes}

Among the germs that do not have the ESBL phenotype, we found other resistance phenotypes to bêta-lactams whose impact on the bacterial resistance is not negligible. Indeed, 13 PHN phenotypes, 11 PBN, 6 TRI, 4 CPL, 3 CHP, 1 loss of Orp D2 porine have been recorded. This observation increases the phenomenon of resistance taking into account that the ESBL producing strains come from these pénicillinases changes.

No carbapenemase producing strains have been found. This is explained by the low availability of carbapenemase in our regions and its high cost; that is why it was found only in previous therapy of only 3 patients among the 106 entering the study which equals $2.8 \%$.

Among the germs having the ESBL phenotype, 94.3\% manifested a resistance phenotype to at least one quinolone and one aminoglycoside at the same time; $100 \%$ of ESBL producing germs manifested a resistance phenotype to at least 3 different antibiotic families. These results confirm the observation by Boyd DA, et al. [1] which found that ESBL are carried by large size plasmids which very often contain resistance genes to other antibiotic classes thus making the host bacterium multi-resistant [13-24].

\section{Conclusion}

From our study it is observed:

110 BGN isolated for 106 patients (101 EB + 9 other BGN).

$E$ coli are the predominant species mainly found in urine followed by K pneumoniae.

About half of our isolates (48.2\%) were ESBL+.

The hospitalised patients had more risk to have an ESBL phenotype than out-patients.

TRI, PHN, PBN, CPL, CPH penicillinases have also been observed.

The assessment shows the importance of the phenomenon and should help for a better care provision for this scourge, for antibiotics (ATB) after all, still save millions of lives.

\section{References}

1. Boyd DA, Tyler S, Christianson S (2004) Completed nucleotide sequence of a 92-kilobase plasmid harboring the CTX-M-15 extended-spectrum- beta-lactamase involving in the outbreak in long-term-care facilities in Toronto, Canada. Antimicrob Agents Chemother 48: 3758-3764.

2. Course on aminoglycosides visited October 20, 2014. Avalable from: www. pharmaetudes.com/ressources/.../section5/27-aminosides.pdf.

3. Dabiré M (2013) Molecular and kinetic characterization of broad-spectrum ß-lactamase (ESBL) types of isolated bacterial strains at the Charles De Gaulle Pediatric University Hospital Center (CHUP-CDG) [Thesis for the PhD]. Ouagadougou: University of Ouagadougou.

4. Dye D, Croize J, Brambilla C (1995) Antibiotic resistance mechanism of bacteria responsible for respiratory infections. Rev Wrong Resp 12: 415-427.

5. Data sheet: Acinetobacter baumanii available on the website of the Toulouse Center for Quality Control in Clinical Biology: www.ctcb.com.

6. Gassama A, Boye CS, Ndir I, Kairé O, Coly I, et al. (1999) [Micromethod for identification of enterobacteria]. Dakar Med 44: 69-75. [Crossref]

7. Guessennd N, Kacou-N'douba A, Gbonon V (2006) Prévalence et profil de résistance des entérobactéries productrice de bèta-lactamases à spectre élargi à Abidjan Cote d'Ivoire de 2005-2006. J Sci Pharm Biol 1: 63-70.

8. Gniadkowski M (2008) Evolution of extended-spectrum beta-lactamases by mutation Clin Microbiol Infect 14 Suppl 1: 11-32. [Crossref]

9. Jehl F (2000) Why and on what basis change breakpoints. SYMPOSIUM "Changes in critical values: impact on bacterial antibiotic resistance surveillance".

10. Jacob G (2010) Emergence of Enterobacteriaceae Secreting Broadleaf BetaBactamases. Pp: 438.

11. Jehl F, Chomarat M, Weber M (2003) De l'antibiogramme à la prescription. Editions Biomérieux, 2003 Mars.

12. Jones RN, Pfaller MA (2003) Antimicrobial activity against strains of Escherichia coli and Klebsiella spp. with resistance phenotypes consistent with an extended-spectrum ß-lactamase in Europe. Clin Microbiol Infect 9: 708-712.

13. Lafaurie M (2008) Aminosides and Fluoroquinolones.D.U Antibiotics and antibiottherapy. St. Louis Hospital. Pp : 63-64.

14. Laffineur K, Janssens M, Charlier J, Avesani V, Wauters G, et al. (2002) Biochemical and susceptibility tests useful for identification of nonfermenting gram-negative rods. $J$ Clin Microbiol 40: 1085-1087. [Crossref]

15. Livermore DM (1995) beta-Lactamases in laboratory and clinical resistance. Clin Microbiol Rev 8: 557-584. [Crossref]

16. Lonchel CM, Meex C, Gangoué-Piéboji J (2012) Proportion of extended-spectrum beta-lactamase-producing Enterobacteriaceae in community setting in Ngaoudere, Camerooon.

17. Obeng-Nkrumah N, Twum-Danso K, Krogfelt KA, Newman MJ (2013) high levels of extended-spectrum beta-lactamases in Major Teaching Hospital in Ghana : The Need for Regular Monitoring and Evaluation of Antibiotic Resistance. Am J Trop Med Hyg 89: $960-964$. 
18. Ouédraogo AS, Somé DA, Dakouré PW, Sanon BG, Birba E, et al. (2011) [Bacterial profile of surgical site infections at Souro Sanou National Hospital Center in Bobo Dioulasso, Burkina Faso]. Med Trop (Mars) 71: 49-52. [Crossref]

19. Richard C, Keredjian M (1995) Laboratory methods for the identification of strict aerobic gram-negative bacilli: Pseudomonas, Alcaligenes, Flavobacterium, Acinetobacter, Brucella, Bordetella. Inst Pastor 2eédition 2: 22-26.

20. Rodriguez-Villalobos H, Struelens MJ (2006) Bacterial resistance by extended spectrum $ß$-lactamases: implications for the resuscitator. Microbiology Department, Erasme-Free University Hospital, Brussels, Belgium.
21. Roussel-Delvallez M (2007) Du bon usage des antibiotiques en établissement de santé ; Des ß-lactamines aux fluoroquinolones. CHRU - Lille.

22. Sangare SA, Maiga AI, Guindo I, Maiga A, Camara N, et al. (2015) Prevalence of extended-spectrum beta-lactamase-producing enterobacteriaceae isolated from blood cultures in Africa. Med Mal Infect 45: 374-82.

23. Storberg V (2014) ESBL-producing Enterobacteriaceae in Africa - a non-systematic literature review of research published 2008-2012. Infect Ecol Epidemiol 4: 50-55.

24. Sougakoff W, Trystram D (2003) Resistance to B-lactams. Pierre and Marie Curie University. Medical School.

Copyright: (C2017 Sanou M. This is an open-access article distributed under the terms of the Creative Commons Attribution License, which permits unrestricted use, distribution, and reproduction in any medium, provided the original author and source are credited. 